\title{
CONSUMER RELEVANT ONLINE COMMUNICATION CHANNELS IN CZECH REPUBLIC IN THE CONSUMER GOODS CATEGORY
}

\author{
Farková, A., Lhotáková, M.
}

\begin{abstract}
A lot has been said and written about online communication in the past several years, and just as any new phenomenon, online communication is a disputable topic in many companies. The objective of this article is to analyse the behaviour of Czech consumers online and their preferences for the different online communication channels in the consumer goods category. We have examined what digital media are and how companies can use them, including a close examination of the Czech Internet population. As many of the research studies and data lead to different conclusions, especially concerning communication on social media, we have decided to apply the theoretical knowledge on a case of the Tassimo brand, a capsule coffee machine maker. This study lead us to the conclusion that consumer relevant online communication is about ensuring easily accessible clear information, especially via websites, reviews and recommendations, while social media play a minor role at the moment.
\end{abstract}

JEL classification: M37

Keywords: online communication; digital media; social media.

\section{Introduction}

Over the last decade there has been an immense improvement in the communication technologies influencing the behaviour and interaction among people and businesses. New digital media enabled companies to target their customers more precisely and effectively, along with their ability to gather vast amounts of data about the customers' needs and wants (Pride, 2012, p. 282). It is a must to be online, as there is a broad variety of online media channels; marketers must carefully evaluate them and choose the best one for their communication with consumers.

The objective of this article is to analyse the behaviour of Czech consumers online and identify the most appropriate and suitable online communication channels and content. As many of the research studies and data lead to different conclusions, especially concerning communication in social media, the consumer habits and preferences in online communication in the Czech Republic per the case of the Tassimo brand, a capsule coffee machine maker, were examined. This brand was selected since it is in the second most purchased product category online in the Czech Republic - electronics; therefore considered a very relevant example. Based on the overview of relevant literature concerning digital communication, the benefits of the different channels were examined, along with the methods of evaluation and content that can be shared through the different channels. To prove or disapprove these findings for the Tassimo brand, primary research was carried out among respondents from the company's database. Primary research was conducted to find out how to communicate online with consumers most effectively in the Czech Republic, and identify their expectations from brand's online communication.

\section{Digital Media and Their Benefits for Marketing Communication: Theoretical Outcomes}

There are many different online communication channels, including social media, websites, blogs, or product review sites that companies can use to communicate with their customers. Each one of these channels provides the company with different benefits, ranging from increased brand awareness to encouraging customer feedback, or increasing sales. Here we briefly evaluate the most common online communication channels 


\section{Social media}

The benefits of social media sites, with a focus on Facebook, are the most disputable ones, as there are many different points of view on this topic. On one hand, it is argued that social media users are not too busy with communicating with their friends and they do have the capacity to notice marketers (Ryan, 2011, p. 16). Also comScore's report on the topic of social media marketing effectiveness provides a prime example of effective advertising, namely the Samsung ad campaign for Galaxy S3 that reached an astonishing " 105 million unique users and generated $\$ 129$ million in sales, a 13-times return on a $\$ 10$ million ad buy" (Farber, 2012). Apart from effective advertising, it is claimed that Facebook can also increase online sales, get users to follow the brand, or just "create a platform where customers can discuss the products and... spread the word" (Qwaya, 2013), arguing that there is a range of different benefits social media, namely Facebook, can provide.

On the other hand, numerous articles claim the benefits are very limited, especially the possibility to sell through Facebook. As Sucharita Mulpuru, an analyst at Forrester Research in Cambridge, Massachusetts stated, "it is like trying to sell stuff to people while they're hanging out with their friends at the bar" (Lutz, 2012). This finding is supported by the experience of GM that found paid ads ineffective, and now they are on Facebook only with their "aggressive content strategy with all of [their] products and brands, as it continues to be a very effective tool for engaging with [their] customers" (Tsukayama, 2012).

There are clear benefits from communication via Facebook, especially in observing what the customers do, what their interests are, and sometimes it is also possible to engage with them. However, "Facebook doesn't really differ from mass media. It's great to get decent reach, but to change the way people interact with a brand overnight is just unrealistic" (Murphy, 2012). Also as Tomáš Feige notes, "Facebook offers five major communication channels for brand pages - via commenting, regular status updating, posting links and sharing photos or videos" (Feige, 2013).

Another issue with social media is how to evaluate its effectiveness. Recently, tools have been developed that enable marketers to evaluate the performance of social media, such as Social Bakers or Zuum. They mostly enable companies to compare their page with the competition, based on different statistics, such as engagement level on posts measured over time. Facebook also offers page owners the Facebook Insight tool to get an overview of who their fans are, how successful their content is, measured mainly by engagement levels. These tools allow companies to easily evaluate their social media communication and identify changes needed to improve their online communication.

\section{Webpage}

A websites is a basic communication channel every company must have since it is a low cost way of making the company visible online. The key to making a website successful is not only including relevant content for the visitors, but also ensuring website optimization for search engine searches, the so-called search engine optimization (SEO), since search engines are the biggest source in generating leads, as the study State of Digital Marketing Reports from 2011 claims (McGee, 2011, p. 6). One helpful tool for evaluating the performance of websites in terms of the content is Google Analytics, and the Google AdWords Keywords Tool can assists with SEO.

\section{Blog}

Blogs, another online communication channel, are a great way to share experiences with others, and they can exist on their own as part of a product's website. There are numerous benefits to having blogs on the web, such as: increased traffic, better search engine positioning, and giving a personality to the website, as blog posts are "written by real people with visible personalities in the writing style" (Potts, 2007, p. 197). Blogs are a great way of providing product information to potential customers.

\section{Online review}

Online reviews and recommendations are becoming increasingly important as eCommerce grows. Although, customers' reviews can't be influenced by the company easily, the company's response can be managed, thereby greatly influencing the brand image, especially in response to a negative comment. There are several key steps a company should follow when dealing with a negative review, as stated by Lisa Barone: firstly listen, be honest, remain calm, speak like a human without any jargon, and promise the customers to improve (Barone, 2009), which shows the customers the company's interest, and thereby influences the company's image.

Clearly, there are many different online communication channels and new tools and ways for measuring communication effectiveness; therefore, it is important for companies to be up to date and ensure the best use of technology to their advantage.

\section{Online Communication in the Czech Republic}

As the focus of this article is on online communication in the Czech Republic, it is essential to examine the Internet 


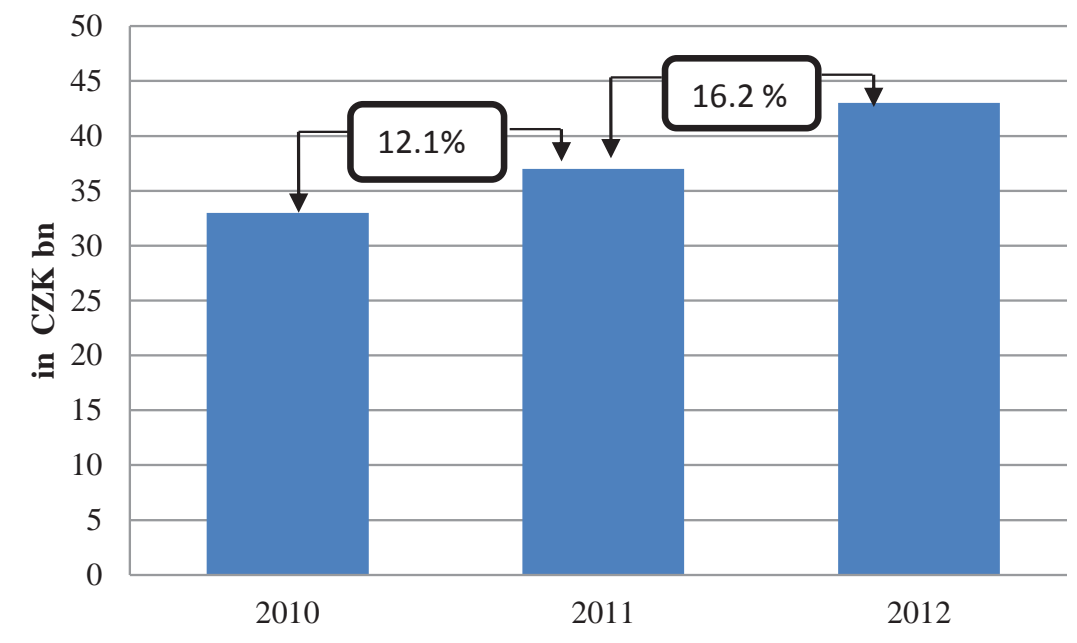

Graph 1 Total Revenue of Czech Internet Retailers

Source: Authors based on http:// www.ceeitandtelecom.com/180149/ Czech-e-sales-out-performed-prioryear-by-CZK-6bn-in-2012.shtml population and its characteristics. The data from June 2012 state that there are 7,220,732 Internet users in the Czech Republic, a $70.9 \%$ penetration of the population (News Media Trend Watch, 2013), suggesting high importance of online communication.

From companies' point of view, eCommerce statistics are of great interest. As shown in Fig. 1, the revenues of Czech Internet retailers have been growing over the past few years, and in 2012 the revenue reached CZK 43 billion (PMR, 2013).

The study also concluded that the majority of online shopping is done by Internet users aged 25-34, followed very closely by the group aged 16-24, and the highest amounts in Czech online shopping baskets were spent on white goods, followed by electronics" (yStats.com, 2012). This may suggest that it is most likely the younger generation below 34 years of age that the companies should focus on communicating with, and encouraging to buy online.

It is also essential to examine the behaviour of Internet users. Based on the results of a report conducted by TNS AISA for the Czech Republic in 2009, which examined 2,000 participants in the age group $15-69$, it is clear that $55 \%$ of users are passive, and just $45 \%$ are active (Salomon, 2010), as shown below in Fig. 2.

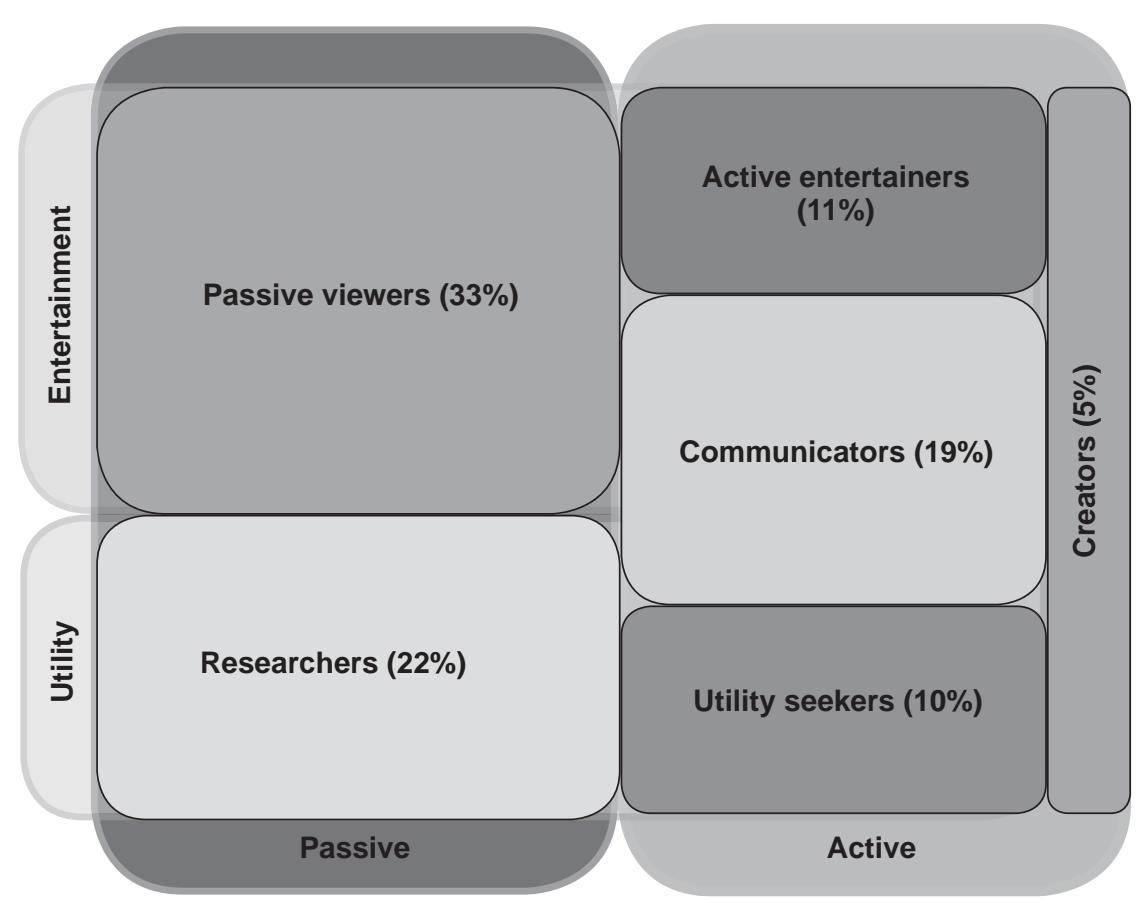

Figure 2 Types of Internet Users in the Czech Republic

Source: Salomon (2010) 
There are just $11 \%$ creative users, and also the group of communicators is very small, only $19 \%$. These are Internet users who chat, write blogs, and discuss issues on the Internet (Salomon, 2010), which companies should keep in mind when trying to engage the customers in online discussions and communication, as generally a relatively low response should be expected.

When looking at the different online communication channels, a website is a must for each company, and to ensure its success, it is important to optimize the sites for search engine searches, as a full $26 \%$ of Czechs start their Internet sessions on a search engine or service site (Salomon, 2010), underscoring SEO importance. In the Czech Republic, companies should be optimizing their sites mainly for Google.cz, which as of 2011, took over leadership from Seznam.cz (Skálová, 2011) - which, however, remains a very strong number two.

Over the past few years, there has been a boom observed in the number of companies present in social media, especially on Facebook, the number one social site worldwide with 1.11 billion monthly active users (Smith, 2013). In the Czech Republic, Facebook has also been the leader since the middle of 2009 (Dočekal, 2012), and currently there are 3,849,900 Facebook users in the country (Socialbakers, 2013).

Social sites are becoming a popular communication channel, and to succeed, it is essential to know why Internet users are present on these sites. An empirical study from 2010 concluded that the top three reasons are connected to the development and maintenance of the offline social life of the users (Karlíček et al., 2012) as shown below.

Companies need to try and find ways to link their online activities with the offline life of the users. This can be in the form of offline competitions, events, or other activities that are then just communicated or shared via social networks. Companies that have a Facebook page should be aware of the fact that $32.8 \%$ of the respondents of a study claimed they use social media to gather some hints, advice, or recommendation and $15.4 \%$ go onto social media to solve problems (Karlíček, 2012). This fact is supported also by another research report, Czech Firms in Social Media, and its conclusions about what has and has not worked for Czech firms on Facebook; the results are presented in Table 2.

\section{Table 1 Reasons to participate in social networking sites}

\begin{tabular}{|l|r|}
\hline To be in touch with friends & $84.7 \%$ \\
\hline Planning activities with friends & $48.7 \%$ \\
\hline Organizing events & $34.2 \%$ \\
\hline Obtaining hints, advice, recommendations & $32.8 \%$ \\
\hline Promoting myself or my activities & $22.0 \%$ \\
\hline Finding new friends & $16.8 \%$ \\
\hline Finding business oportunities & $16.2 \%$ \\
\hline Solving some problems & $15.4 \%$ \\
\hline Flirting & $9.2 \%$ \\
\hline Nothing in particular & $2.6 \%$ \\
\hline
\end{tabular}

$\mathrm{N}=640$

Source: Karlíček et al. (2012).

It is rather clear that information about the company, its products and promotional activities are important to Facebook users, as well as being treated as a privileged member of a group, this means receiving discounts and receiving information first. This is what companies should do on Facebook.

Table 2 Successes and failures on Facebook

\begin{tabular}{|l|l|}
\hline Worked & Did not work \\
\hline Information about the company & Attempts to get and retain active users \\
\hline Communication - especially against negative comments & Using application to increasing the number of fans \\
\hline Applications & Facebook presence did not impact the attendance of company events \\
\hline Steady fan build-up, not through advertising & Posting of random pictures on the page \\
\hline Information about discounts & PPC advertisements did not work \\
\hline People react to silly/fun posts & Deleting comments- it tends to backfire \\
\hline Discussion/answering questions & Not answering questions looks bad \\
\hline Group messages to fans with a link to company website & Organizing competitions for the fans \\
\hline Photos from events posted on the page & $\begin{array}{l}\text { Lack of interest to become a fan of a place/organisation one belongs } \\
\text { to already anyways }\end{array}$ \\
\hline
\end{tabular}

Source: Dočekal (2012). 


\section{How to Communicate Online on the Czech Market: Learnings from the Tassimo Brand}

To better understand online communication channels and their suitability in the Czech Republic in the consumer goods category, the case of Tassimo was studied, where primary research was conducted to confirm whether secondary research data reflect the reality on the Czech market. Tassimo is a capsule coffee machine/hot beverage machine maker brand that was introduced in the Czech market in November of 2011 by Mondelēz Czech Republic s.r.o., owning among others Jacobs Krönung, Milka and Twinnings brands, which are all used in the T-discs, Tassimo machine's capsules, on a co-branding principle. Tassimo is positioned as a hot beverage machine, providing a variety of drinks at a push of a button. Simplicity of use and sophistication are its key attributes. The strategy is now focused on sale of machines, and building up of a customer base for T-discs.

Concerning communication, Tassimo has been focusing predominately on increasing awareness through traditional advertising, billboards and TVC, as well as in-store sales. For online communication, the website and Facebook are used; however, the Tassimo brand does not have its own Facebook page, and it currently communicates through the Jacobs Krönung page.

The situation and competitive analysis identified several shortcomings in online communication, and to better understand consumer behaviour online, primary research was conducted examining the online communication and preferences of Czechs regarding the Tassimo brand. After considering the most suitable target group, a survey was conducted among people in the company's database. These people have previously engaged in online communication with the company, showing they are active Internet users; thus, the relevant target group audience, as active Internet users, may show preferences for different online channels. There were two versions of the questionnaire that were prepared and sent out to the respondents, split between owners of the Tassimo coffee maker and non-owners.

The questionnaire examined what online communication channels Czechs use to find information about Tassimo, or other electronic products, and the prioritization of these channels. It also examined what type of data Internet users mostly look for, and what their expectations from a website and a registration with a brand are. Also, the online behaviour of the respondents was examined, namely, determining their level of engagement - i.e. are they more active or passive users - by examining if they recommend/review products online. As this survey examined only a sample of 112 Czech Internet users, it may not be fully representative of the whole Internet population, and some niches might have been omitted.

Despite this limitation, we believe that for the purpose of proving or disapproving the results of the secondary research for the case of Tassimo brand, the extent of this survey was sufficient.

\section{Results}

The survey was able to identify clear preferences of Czechs with regards to online communication, what type of information they look for, and how they like to search for information, which allows companies to improve their online communication and match Internet users' preferences.

Regarding the online channels, the survey identified websites of products to be the most used channel for gathering information, namely $45 \%$ of owners and $37 \%$ of non-owners choose it as a channel they use. The website was followed by sites that compare prices of products, and third are references/recommendations. On the fourth place were social sites, but in both cases only around $8 \%$ of respondents use this channel to get information about a product. Concerning the importance of channels, the survey found that the most important channel mentioned was mainly references/ recommendations of products, followed by website, and the Internet. The answer 'Internet' is being interpreted as the use of search engines. The high importance of the Internet underscores the importance of optimizing websites for search engines, as the theory suggested. A summary of the results is provided in the table below. It was also concluded that the main expectation from a product's website is a clear description of the product, which ranked number one, with $83 \%$ of the respondents choosing it. It is also very important for the website's visitors that the main benefits of the products are outlined clearly, along with recommendations and experience of the current owners of the product. Videos were ranked on the fourth place, out of the seven options, by $28 \%$ of the respondents, suggesting it's also relatively important. Respondents stated that they most often search for text, followed by photos and then videos. However, when looking at the competitive analysis and the popular type of media used in social sites, photos along with videos are then the most important ones, and those that lead to the highest engagement levels (Zuum, 2013); companies should incorporate them into their online communication. Not only it is something Internet users engage with, but it is also a great method of describing a product and introducing its benefits, which is what website visitors want to find there. 
Table 3 Summary of responses to the question: What are the two most important sources of information when choosing an electronic product/coffee maker?

\begin{tabular}{|l|c|c|}
\hline Channel & Non-owners & Owners \\
\hline References/recommendations & $34 \%$ & $33 \%$ \\
\hline Website & $27 \%$ & $20 \%$ \\
\hline Internet & $18 \%$ & $23 \%$ \\
\hline Comparison sites & $11 \%$ & $8 \%$ \\
\hline Advertisements (TVC, leaflets) & $7 \%$ & $18 \%$ \\
\hline Blogs & $3 \%$ & $0 \%$ \\
\hline Social media & $2 \%$ & $3 \%$ \\
\hline
\end{tabular}

Source: Author

The recommendations and reviews of products are very important to Czech online users as well, and the study concluded that roughly $20 \%$ do write online reviews themselves, which is in fact in line with the statistics presented in the AISA study. In order to be able to provide potential customers with sites full of product reviews and recommendations, companies firstly need to find ways to encourage visitors to write these, as $20 \%$ will not suffice. Research found that firstly, it is essential that a company makes an effort and asks for a review. This can be done either directly on the page where customers have purchased the product, or companies also often use email. They send an email shortly after the delivery of the products, while the product is still new and exciting, thus increasing the likelihood of a response to an email asking for a review. It is essential for the writing of reviews and rating of products to be simple and visible immediately for new visitors of the website (Moth, 2013). Companies can also utilize their presence in social media and encourage brand followers to review products or write recommendations, either on the social site itself, the product website, or any other page set up for online product reviews. Marketers can also focus on communication with opinion leaders. For example, they can sample innovative products with them and thus stimulate WOM. This tool is known as "product seeding" (Karlíček, Tomek and Křížek, 2010).

Many brands are encouraging customers to register with them after purchase, and it is essential to communicate and meet the customers' expectations from such a registration, as it can greatly influence the brand's image and reputation. The market research clearly showed that customers expect coupons/discounts as well as newsletters and information about new products. The two most preferred channels identified by the study for such communication are e-mail and product website. However, when looking at the results from the owners of the Tassimo machine only, then their second choice, $40 \%$ of the time, was social media.

Despite the research identifying social media as a non-essential communication channel, there is some information that suggests otherwise. The study found that $70 \%$ of the respondents would become fans of a Tassimo Facebook page. Additionally, the highest growth in Facebook users is in the age groups 35-44 and 45-54 (Socialbakers, 2013), which is the age group that was examined in this survey and is relevant for Tassimo brand. If we assume this trend keeps up and social media users will remain using it as they get older, then the relevance of Facebook will become increasingly important in the future for companies targeting the middle aged and older Czechs. Thus, although social media are not essential at the moment, it's important to keep an eye on it for the future. The research found that respondents would like Facebook to be a source of information regarding any new or planned products that will be on offer, and information about discounts or access to special offers would also be welcome. This is important for companies to note and implement when, and if, they set up Facebook pages.

\section{Conclusion}

The objective of this research was to examine the preferences of Czech consumers for different online communication channels via the case of the Tassimo brand in the Czech Republic. Firstly, the focus was on reviewing some literature and theories regarding online communication. What digital media are and how companies can use them and benefits from them was examined, along with the usage of digital communication focusing on the Czech Internet population.

The secondary research focused on the target audience of the Tassimo brand, and the results were used to define ways to effectively communicate with the Czech online population. The primary research was done in the form of an online questionnaire.

In general, the study found that suitable online communication in the consumer goods category is first and foremost about clear communication via a website, which should include relevant content, mainly simple and clear presentation of the product and its benefits, as well as optimization of the website for search engines, as they are one of the most important channels Internet users use to search for information. Also, customers shop increasingly more online; they also search for reviews and recommendations there. Consequently, it is important for companies to monitor these, to ensure they stay up to date with what the customers are saying, 
support them and engage in conversation. Facebook and other social media proved to be of lower importance for brands' communication at the moment, but their relevance may increase in the future for companies targeting middle aged consumers.

Furthermore, it is necessary to ensure that the offline and online communication is aligned, to avoid confusion, and interlink online channels to ensure Internet users are able to easily find all the information they are looking for, or information that might be of interest to them.

\section{References}

AISA (2010). Češi v síti. Prague: TNS AISA.

Barone, L. (2009). How Companies Should Respond To Negative Reviews, (accessed June 27, 2013), [available at: http://outspokenmedia.com/reputation-management/ respond-negative-reviews/].

Dočekal, D. (2012). České firmy v sociálních sítích. Lupa.cz.

Farber, D. (2012). Facebook ads really work, just ask Samsung, (accessed March 9, 2013), [available at: http://news.cnet.com/8301-1023_3-57554791-93/ facebook-ads-really-work-just-ask-samsung/].

Feige, T. (2013). Social Media Marketing - Analysis of Online presence of Slovak banks. Journal of Systems Integration, 4(3): 20-29.

Google (2014). Alerts. Retrieved from http://www.google.com/ alerts.

Karlíček, M., Tomek, I., Hasprová, M., Zamazalová, M. (2012). Social networking sites in the Czech Republic: An empirical study. Management \& Marketing, 7(1): 15-28.

Karlíček, M., Tomek, I. Křǐžek, M. (2010). Word-ofMouth Marketing: An Integrated Model. Ekonomika a management, 2010(3).

Lutz, A. (2012). Gamestop to J.C. Penney Shut Facebook Stores, (accessed March 16, 2013), [available at: http:// www.bloomberg.com/news/2012-02-17/f-commerce-tripsas-gap-to-penney-shut-facebook-stores-retail.html].

McGee, M. (2011). SEO Beats PPC \& Social Media For Generating Leads, New Industry Report Says, (accessed March 16, 2013), [available at: http://searchengineland.com/ seo-beats-ppc-social-media-for-generating-leads-99064].

Moth, D. (2013). 10 ways to encourage customer reviews online, (accessed June 27, 2013), [available at: http:// econsultancy.com/cz/blog/61677-10-ways-to-encouragecustomer-reviews-online].

Murphy, D. (2012). Study: Facebook Fans Just Don't Engage Brands, (accessed March 16, 2013), [available at: http:// www.pcmag.com/article2/0,2817,2399507,00.asp].

News Media Trend Watch (2013). (accessed March 5, 2013), [available at: http://www.newmediatrendwatch.com/ markets-by-country/10-europe/43-czech-republic].
NICE (2013). Voice of the Customer, (accessed June 27, 2013), [available at: http://www.nice.com/ voice-of-the-customer-solutions].

PMR (2013). Czech e-sales out-performed prior year by CZK $6 b n$ in 2012, (accessed March 5, 2013), [available at: http://www.ceeitandtelecom.com/180149/Czech-e-salesout-performed-prior-year-by-CZK-6bn-in-2012.shtml

Potts, K. (2007). Web Design and Marketing Solutions for Business Websites. USA: Apress.

Qwaya (2013). Facebook for business, (accessed March 9, 2013), [available at: http://www.qwaya.com/ facebook-for-business].

Ryan, C. J. (2011). The Best Digital Marketing Campaigns in the World: Mastering The Art of Customer Engagement. London: Kogan page Limited.

Salomon, P. (2010). Češi v síti. Prague: TNS AISA.

Skálová, V. (2011). Google v Česku zvítězil nad Seznamem, poprvé v historii, (accessed June 27, 2013), [available at: http://aktualne.centrum.cz/ekonomika/penize/clanek. phtml?id=687697].

Smith, C. (2013). By the Numbers: 16 Amazing LinkedIn Stats. (accessed June 27, 2013), [available at: http://expandedramblings.com/index.php/ by-the-numbers-a-few-important-linkedin-stats/].

Socialbakers (2013). Facebook Pages Statistics \& Number of Fan (accessed March 17, 2013), [available at: http://www. socialbakers.com/facebook-pages/brands/].

Tsukayama, H. (2012). Ahead of IPO, Facebook loses GM ads. Získáno 16. 3 2013, z Washington Post: http://www. washingtonpost.com/business/technology/ahead-of-ipo-facebook-loses-gm-ads/2012/05/15/gIQAzCLLSU_story.html

Pride, W. M, Ferrel, O. C. (2012). Customer Behavior and E-Marketing. Mason: South-Western.

yStats.com (2012). Czech Republic B2C E-Commerce Report 2012, (accessed March 5, 2013), [available at: http://ystats. com/en/reports/preview.php?reportId=997].

Zuum (2013). My Report, (accessed April 29, 2013), [available at: http://www.zuumsocial.com/users/michaljanovsky/ reports/58618930].

\section{Authors}

Ing. Alena Farková

Swiss Reinsurance Company Ltd., Mythenquia 50/60 8022 Zurich, Switzerland alenafarkova@yahoo.com

Ing. Markéta Lhotáková Ph.D. University of Economics, Prague Faculty of International Relations Department of International Trade Winston Churchill Sq. 4, 130 67, Prague 3, Czech Republic marketa.Ihotakova@vse.cz 